\title{
Fundamentos para una consideración filosófica de la historia de la música
}

\author{
Max Gottschlich ${ }^{*}$
}

\begin{abstract}
Resumen: El texto desarrolla los lineamientos generales de una interpretación inspirada en el pensamiento de Hegel de los comienzos de la historia de la música occidental hasta el inicio de la Edad Moderna musical. La historia de la música previa a la de la modernidad es analizada como una historia de consumación en el sentido de que en ella el concepto -entendido este término como lo hace Hegel- llega a presentarse de un modo cada vez más concreto en el elemento de la sensación.
\end{abstract}

Palabras clave: Filosofía de la música, Estética, Filosofía del arte, Hegel

\section{Foundations for a philosophical consideration of the history of music}

Abstract: The text develops the general guidelines of an interpretation inspired by Hegel's thought of the beginnings of the history of Western music until the beginning of the musical Modern Age. The history of music prior to that of modernity is analyzed as a consummation story in the sense that in it the concept -understood this term as Hegel does- comes to be presented in a more and more concrete way in the element of the feeling.

Key words: Philosophy of music, Aesthetics, Philosophy of art, Hegel

* Doctor en Ciencias Musicales por la Universidad de Viena (2005) y Doctor en Filosofía, asimismo por la Universidad de Viena (2009). Ha sido docente en la Universidad de Viena y en la Universidad Johannes Kepler de Linz; desde 2015 es Profesor Asistente de la Cátedra de Filosofía Práctica y Ética en la Universidad Católica de Linz. Entre 2014 y 2015 fue Profesor Visitante en el Departamento de Filosofía de la Universidad de Warwick, Reino Unido. Ha publicado un libro, compilado seis y publicado varias decenas de artículos en revistas especializadas y colecciones de artículos aparecidas en Europa, Estados Unidos y América Latina. Dirección electrónica: $\underline{\text { m.gottschlich@,ku-linz.at }}$ 
¿Cómo debemos pensar la música? Dos posiciones unilaterales deben ser evitadas:

(1) La primera se vincula con la tesis del historicismo: las músicas de todas las épocas son siempre buenas, acabadas y bellas "a su manera," puesto que han de ser comprendidas "a la luz de su tiempo." Así las cosas, la Humanidad vive siempre en un tiempo de grandes obras y genios originales, y la música, en cada caso actual, es la respectiva gran música de su tiempo. Pero entonces sería un sinsentido hablar en singular de la historia de la música, pues la historia de la música se descompone sin unidad interna en una multiplicidad de obras; ella sería sólo un constructo que se descompone en una narrativa cualquiera y en su perspectivismo. Si podemos poner en un mismo nivel las unas con las otras a las músicas de todas las épocas, podemos entonces organizarlas de la manera que queramos y disponer del modo que nos plazca lo que llamamos "historia de la música"1. El historicismo es, fundamentalmente, nominalismo puesto en práctica, un pensamiento radicalmente técnicopráctico y ahistórico. Esto nos conduce a la segunda posición unilateral:

(2) Ésta consiste -y utilizo esta expresión técnica en forma conscienteen el operar con un concepto universal abstracto de la música, en una definición esencial metahistórica que tiene debajo suyo todos los fenómenos históricos singulares tan sólo como casos, con lo cual éstos quedan, en última instancia, fuera de ella, y no se les hace justicia o se les ejerce violencia. También aquí carece finalmente de sentido hablar de una "bistoria de la música", pues tampoco aquí puede haber algo así como desarrollo y progreso: el retorno de siempre lo mismo no es historia.

${ }^{1}$ Se afirma así, por ejemplo, que La flauta mágica de Mozart es el primer musical, que Elton John es nuestro Schubert y que Beethoven es un precursor de Schönberg (así lo dice Adorno). Nuestras experiencias musicales - pensemos en los conciertos que desde el siglo XIX concebimos por lo general como una mezcla de estilos- parecen avalar esta visión del historicismo. También el artista es habitualmente de la opinión que la música que está ejecutando es la mejor. Y el moderno consumidor de música que elabora siguiendo su estado de ánimo una lista de canciones o la hace elaborar por una app (por ejemplo, composed.com) estaría de todas formas de acuerdo con esto en el carácter privado de su gusto (Geschmacksprivatismus). 
El presupuesto fundamental de ambas concepciones radica en la suposición insostenible de una esencia suprahistórica de la música que es constantemente actualizada de nuevo por un "genio." Los cambios de material, forma y contenido en los estilos, los géneros, los modos de movimiento y estructuras sintácticas serían entonces sólo fenómenos accidentales de la substancia de la música ${ }^{2}$. Si nos preguntamos qué es esta esencia ahistórica de la belleza musical, obtendremos como respuesta sólo determinaciones formales: "siempre ha habido buena y mala música", o "lo musicalmente bello es la melodía que más le gusta a la mayoría"3.

Como vemos, nuestra pregunta acerca de la comprensión adecuada de la historia de la música coincide con la pregunta acerca del concepto adecuado de la música. Responder a estas preguntas no cae ya en la esfera de competencia de la ciencia de la música, sino más bien en la de la filosofía. Y aquí podemos adelantar una respuesta, en contraste con muchos enunciados de la Estética, es decir, de la filosofía del arte: el concepto adecuado de la música debe revelarse como un universal concreto que se particulariza a sí mismo. Es a partir del concepto mismo que debe emerger la necesidad de considerar a la historia como la particularización o autoexplicación del concepto ${ }^{4}$. Esta tesis, que

2 Así, por ejemplo, también Schönberg se presentó todavía a sí mismo como un genio natural. Las tres fundamentaciones últimas del genio musical en la modernidad que son traídas a colación y entremezcladas a gusto son: 1) por gracia divina, 2) alguien que, favorecido por la naturaleza, tiene el poder de conferirle al arte nuevas leyes, 3) sismógrafo sufriente de la sociedad que refleja de modo crítico los sufrimientos y contradicciones de su tiempo. Cfr. Leo Dorner, Das Philosophon: Essays zur Musik, Würzburg, Königshausen u. Neumann, 2005, p. 68.

${ }^{3}$ Existe un vínculo interno mutuo entre la nivelación nominalista, es decir, historicista de todas las músicas de todos los tiempos y la pérdida de todo compromiso estético en lo que llamamos "gusto", es decir, entre dicha nivelación y la así llamada "subjetivación" del gusto que termina en la estética arbitraria del mercado de la música. El principio de ambas sostiene que "bello" es lo que se vende bien en el mercado musical. La nominalista arbitrariedad in aestheticis de la modernidad es quizá un resultado necesario de un desarrollo históricamente consumado de la música en la teoría y en la práctica. Cfr. Dorner, Das Philosophon, p. 21.

${ }^{4} \mathrm{El}$ historicismo, por el contrario, sólo conduce a despedirse de los asuntos históricos y abandonarlos a la historia misma. Cfr. Dorner, Das Philosophon, p. 40. 
sostengo apoyándome en Hegel, dice: la historia de la música debe ser comprendida como el desarrollo y consumación de la autonomía y belleza musical. La historia de la música occidental es la historia de la razón musical absoluta, el aparecer del concepto (racional) de la música.

\section{Sobre el concepto de la música}

La filosofía no toma a la música como un mero factum, sino que tiene la necesidad de fundarla como arte, es decir, de deducirla del concepto del hombre. Esto funciona así: el hombre es la unidad sujeto-objeto que se conoce a sí misma, es ser-consciente, esto es, unidad de la relación consigo y de la relación con el mundo, y con ello libertad existente. Libertad significa autodeterminación que se sabe a sí misma. El hombre debe, en cuanto libre, no sólo obrar, sino que debe además elevarse a la conciencia de los presupuestos a partir de los cuales obra, es decir, debe pensar e interpretar su libertad; en caso contrario, el hombre no sería autodeterminación que se sabe a sí misma. Dado que el saberse a sí mismo no es algo inmediato, sino que el hombre adquiere su relación a sí a través del rodeo de la relación con los objetos, este saberse a sí mismo debe atravesar todas las formas inmediatas y mediatas del pensamiento como unidad de la relación consigo y la relación con el mundo, empezando por la sensación, pasando por la intuición y la representación y llegando hasta el pensar en el elemento del concepto, de lo universal. El arte es, junto con la religión y la filosofía, un modo en que el serconsciente se capta e interpreta como esta unidad; es expresión y exposición de la libertad en formas sensibles. Este concepto del arte remite así a la libertad como al contenido del arte en sí mismo, a su particularización histórica, pues la libertad se realiza históricamente siempre de manera particular como conciencia determinada de la libertad.

Esto nos permite ya suponer que la lógica de la aparición de la música debe ser comprendida a partir de esta relacionalidad del arte con la conciencia de la libertad históricamente adquirida. El concepto de la música surge de la siguiente manera: la música es la expresión y exposición de la libertad en el medio del sentimiento, de la sensación. Debemos, en primer lugar, distinguir tres momentos: material, forma y contenido (esto es: el espíritu o el saber acerca de 
la libertad en el modo del sentimiento, de la sensación). El proceso de autorrealización de la razón musical consiste en superar la exterioridad de la forma respecto del material, del material respecto del contenido, asi como de la forma respecto del contenido - y, por cierto, en los planos de la sintaxis, los movimientos, el género, el estilo y la obra individual. Por lo tanto, el sistema tonal, la sintaxis, el movimiento, el género y el estilo son los planos de la unidad entre material, forma y contenido. Podemos suponer que ésta es la clave de la comprensión de la historia de la música europea, la cual debe ser comprendida, pues, de un modo esencialmente entelequial como una historia de consumación (Vollendungsgeschichte).

La unidad entre el material, la forma y el contenido no es una unidad fija, sino una unidad que se mueve, se despliega e individualiza a través de la historia. En este proceso de individuación musical, material, forma y contenido en el plano del sistema tonal, la sintaxis, el género, el estilo y la obra están en sí mismos puestos en correspondencia y mediados el uno con el otro como también en relación con los otros planos. El material y la forma de la música se median en el contenido; el material y el contenido, en la forma; y la forma y el contenido, en el material -y esto siempre en el sistema tonal, la sintaxis, el género, el estilo y la obra. El contenido presupone en cuanto fin el (correspondiente) material y su (correspondiente) forma. Pero la correspondencia entre el material y la forma con el contenido no es otra cosa que su propio respectivo proceso de mediación. La correspondencia del material con el contenido absoluto es la mediación de la forma y el contenido en el material. La correspondencia de la forma y el contenido absoluto es la mediación del material y el contenido en la forma. Así, pues, cada momento de la absoluta unidad del material, la forma y el contenido (y sólo así se trata de una unidad absoluta) es puesto como término medio en el silogismo de la música que tiene como conclusión la unidad concreta de los mismos y, por tanto, es puesto en mutua correspondencia tanto entre sí como en el todo. Puesta en unidad con el contenido (pues éste es el que pone y presupone), la determinidad (Bestimmtheit) cualitativa de la forma de la música (las formas de la reflexión tales como repetición, oposición, etc.) es el conjunto total de la música. Los momentos de esta totalidad no pueden ser considerados, ni práctica ni teóricamente ${ }^{5}$,

${ }^{5} \mathrm{El}$ material en historias naturales de la música (por ejemplo, Heinrich Schenker), la forma en teorías formalistas (por ejemplo, Eduard Hanslick), el contenido en teorías 
como si fueran autónomos: las formas musicales (propias de la reflexión) no son indiferentes respecto del material y el contenido, sino que crecen a partir del material (especialmente la tonalidad) y están siempre unificadas en el contenido absoluto que es sabido de modo histórico, es decir, en el saber de la libertad $^{6}$.

La música no es abstractamente idéntica a su contenido, ni tampoco, en cuanto mero signo del contenido, abstractamente diferente del mismo, sino que simboliza al contenido. Pero en este simbolizar la música remite sólo a sí misma: en el sonido formado la música remite de forma simbólica al contenido (sensaciones determinadas); en este contenido, empero, la música remite retroactivamente a sí misma en cuanto forma ${ }^{7}$. Para la obra musical bella es esencial no quedar detenida en la simbolización del contenido, pues en la obra musical bella tanto el contenido como la forma están puestos como metas en sí mismas. Ambos -forma y contenido- están allí en completa correspondencia y mediación recíproca sólo por sí mismos. En este carácter de ser fines en sí mismos reside la plenitud y belleza posible a la música y realizada en su historia. Al oír esta música, el hombre se conoce y se disfruta como el medio de este proceso de remisión alternante, esto es, como el medio de la correspondencia entre forma y contenido.

del sentimiento (por ejemplo, Friedrich von Hausegger). También Ernest Ansermet suscribe en su Grundlagen der Musik im menschlichen Bewnußsein (München, Piper, 1961) una estética del sentimiento que parte de un contenido estático, metahistórico ("el modo ético de ser del hombre").

${ }^{6} \mathrm{La}$ indiferencia entre material, forma y contenido es puesta recién en la modernidad. Por el contrario, en la historia de la música de Occidente previa a la modernidad el material debe siempre también ser pensado en la historia de las interacciones y los presupuestos de la forma y el contenido; en el contenido, debe ser pensada también su particularización conforme al género, etc. De este modo, también la calidad del material está determinada por el contenido. El contenido en cuanto contenido absoluto (el saber de la libertad propio de un tiempo) determina al material y a la forma de la música.

7 Cf. I. Kant, Kritik der Urteilskraft, Werkausgabe, tomo X (ed. W. Weischedel), Frankfurt/M., Suhrkamp, 1974, p. 272: "In der Musik geht dieses Spiel von der Empfindung des Körpers zu ästhetischen Ideen (Objekte für Affekten), von diesen alsdann wieder zurück, aber mit vereinigter Kraft, auf den Körper." 
Es sumamente importante tomar en serio la historicidad de esta correspondencia entre material, forma y contenido. No hay un ser "absoluto" de formas y contenidos de la música a partir del devenir histórico, sino que cada forma tiene en correspondencia con su contenido su tiempo histórico (el saber de la libertad que es sentido por el hombre de una época), en el cual ella es capaz de recibir en sí este contenido, de convertirlo en poético y de consumarse allí en una historia de la individuación. Consideremos los géneros: al saber de la libertad en una época de la historia de la música corresponde siempre un determinado potencial de libertad acorde a ese género (por ejemplo, en el saber de la libertad de una polis organizada de un modo feudal-corporativo puede consumarse el género "concierto", pero no el género "canción” [Lied]). Un determinado contenido (de libertad) se reúne y cierra sobre sí mismo con una determinada forma en la sintaxis, el movimiento y el estilo.

En el curso de la historia de la música, estas potencialidades de la forma devienen (1) conformadas, (2) realizadas a través de la individuación universal y plena ("clásica"), y (3) con ello al mismo tiempo agotadas y consumidas en su capacidad de expresión, por lo cual nuevas formas sustanciales de expresión deben ser buscadas y encontradas (por ejemplo, alrededor de 1740 la búsqueda tras el Barroco de una nueva expresión "natural" -y algo similar sucede después de Beethoven con el Romanticismo).

El desarrollo sigue, pues, una necesidad interna, a saber: en razón del agotamiento de las posibilidades de expresión y de una autocrítica permanente, el medir-se de la forma alcanzada en el movimiento, el género y el estilo con el contenido que debe ser expresado. ${ }^{8}$ Las potencialidades de libertad del género son compuestas y consumidas de dentro hacia fuera. La vida del género termina cuando se introducen en la obra de arte el quimismo y el mecanismo, es decir, cuando material, forma y contenido ya no se median coherente y concluyentemente en la sintaxis, el movimiento y el estilo, sino que devienen recíprocamente exteriores y la forma interior pierde su fuerza entelequial de superación (por ejemplo, el género fuga después de Bach, el oratorio después de Händel, la sinfonía después de Beethoven o la canción después de Schubert). Expresado en relación con la entera historia de la música este proceso tiene un límite inmanente; este

\footnotetext{
${ }^{8}$ Dorner, Das Philosophon, p. 77.
} 
límite reside en que la capacidad de expresión de la música como lenguaje universal de belleza es sin más agotado en plenas y ya no más graduables individuaciones de géneros y estilos, por lo cual esta capacidad de expresión debe disolverse (éste es el camino necesario hacia la Modernidad; Hegel es el primero en reconocerlo cuando habla del "fin del arte").

¿Cuál es en el proceso de desarrollo en épocas la meta que engloba en sí sus estilos y géneros y los mueve como un motor interno? La respuesta es: la expresión y la exposición de la individualidad humana (de lo bumanus en el sentido de Hegel) y de la plena mediación consigo, es decir, de la autonomía. En la realización de este objetivo -y esto se sigue inmediatamente del concepto de la cosa- la música debe, bajo la forma de la configuración del nivel y duración del tono, conferirle a la forma del movimiento, los géneros y estilos una coherencia o ritualidad interna, cuya estructura fundamental es la siguiente: comenzar y abandonar la unidad, entrar en oposición -incluso en contradicción- y resolverla, y, por último, retornar conciliadoramente a sí mismo. Una forma sonora que expresa esta ritualidad puede expresar el camino del devenir-yo del yo; pues el yo no es sino esto: salir de la inmediatez y entrar en oposición, razón por la cual el yo no se pierde como relación consigo mismo, sino más bien es recién de ese modo como puede llegar a saberse a sí mismo. Resulta ya posible constatar por principio algo más: cuanto más profunda y abarcadora en lo que respecta a la sensación son las contraposiciones en la configuración del tiempo de los sonidos que se disuelven en una unidad conciliadora (ejemplarmente: alegría y júbilo/tristeza), tanto más profunda y abarcadora es la expresión y la exposición del individuo. La realización de esto es la meta y la tarea de la música en su historia.

\section{Sobre la historia de la música}

La condición histórica de posibilidad del desarrollo de la autonomía artística musical es la conciencia de la libertad que se alcanza con el cristianismo. La conciencia de la encarnación del Logos hace posible la comprensión de que el hombre en cuanto hombre es libre y un fin en sí mismo. Con ello la "interioridad" deviene el medio de expresión adecuado del arte. En la base del cristianismo -Hegel habla del "arte romántico"- la pintura, la música 
y la poesía se convierten en artes dominantes. Antes - por ejemplo, en la antigua religión del arte- la música tenía sólo una importancia accidental. Sólo sobre el terreno del cristianismo la música abandona por primera vez en la historia con relativa autonomía su función servicial en el culto y constituye una irrepetible historia de la autonomía. La razón de esto reside en el contenido absoluto del cristianismo, en la idea de la encarnación del Logos. Esto tiene, con respecto al arte, dos aspectos. Por un lado, la música es justificada allí frente a la prohibición bíblica de las imágenes. Así, este contenido absoluto posibilita y exige que el Logos pueda y deba aparecer nuevamente en el arte bajo figuras sensibles, y con ello que el arte oficie por vez primera de órgano de la conciencia religiosa. Por el otro lado, este contenido trasciende al mismo tiempo su posibilidad de ser expuesto con los medios sensibles de las artes. Arte y religión se separan la una respecto de la otra. Con ello, pintura, música y poesía pueden aparecer como figuras relativamente autónomas en el pensamiento de la libertad (el "Espíritu absoluto" de Hegel). Tal autonomía puede realizarse a causa de la potencialmente infinita ampliación ${ }^{9}$ de la capacidad artística y estética que yace en el cristianismo. El entero círculo de la realidad tanto histórica como natural de lo bumanus puede ser asumido en el arte. Es esta ampliación la que hace posible el desarrollo y consumación de la autonomía artística musical.

Hasta aquí sobre los presupuestos del aparecer de la historia de consumación de la música.

La división fundamental de la historia de la música procede del concepto mismo de la música ${ }^{10}$. En cuanto entelequia, la música atraviesa tres fases: (1) surgimiento y desarrollo de un lenguaje musical capaz de autonomía, (2) su consecución y consumación, y (3) su disolución. Si tomamos ahora lo que

${ }^{9}$ G.W.F. Hegel, Vorlesungen über die Ästhetik II, Werke, auf der Grundlage der Werke von 1832-1845, ed. E. Moldenhauer y K. M. Michel, tomo 14, 4. ed., Frankfurt am Main, Suhkamp, 1995, 138ss.

${ }^{10}$ Esta división está regida por una meta; de allí que tenga una unidad y no se fragmente en una multitud indeterminada de narrativas de un entendimiento extrínseco. Si, al modo del historicismo, borramos, en cambio, el telos que reside en el concepto, el material que ofrece el historiador se deja ordenar sólo según criterios en última instancia exteriores y arbitrarios (biográficos, sociológicos, etc.). 
hemos dicho sobre el cristianismo, resulta la siguiente tríada de épocas ${ }^{11}$ :

(1) Una época que va desde el ocaso del canto litúrgico monofónico, el cual comienza a ser escrito a partir el siglo IX, se extiende hasta el comienzo de la Edad Moderna y cuyo comienzo en la música habría que ubicar alrededor del año 160012. Éste es el período de formación de un lenguaje musical capaz de autonomía. La música lleva a cabo este desarrollo en cuanto ella es un medio de la religión en la interpretación y representación de la historia de la salvación, del Logos a partir del cual debe nacer el hombre nuevo. Conscientes de los problemas que acompañan a las periodizaciones y designaciones de épocas, podríamos llamar a este período el "Medioevo musical". ${ }^{13}$

(2) Una época de la "Edad Moderna" musical, que va desde aproximadamente el 1600 hasta el final del siglo XIX. Ésta es la época de la música libre, autónoma (que es un fin en sí mismo), la cual es capaz de expresar y exponer el ideal de un bumanus completo, libre y reconciliado ${ }^{14}$.

(3) La música moderna -la de los siglos XIX y XX- ejecuta, por último, en ella misma mediante la separación de la música "seria" respecto de la música

${ }^{11}$ La división de la historia de la música debe ser un problema permanente, incluso aporético para la musicología. La historiografía musical reflexiona sobre la cuestión de si expresiones como "clásico" son adecuadas para designar lo que deben designar. El historiador puede luego argumentar que algunas designaciones de época -sobre todo "clásico", "romántico", "moderno"- son auténticas porque surgieron en su tiempo como designaciones programáticas y que otras, por el contrario, como "barroco" y "renacimiento", surgieron más tarde y contienen además valoraciones (por ejemplo, ars antiqua) que se han convertido en extrañas para nosotros. ¿Qué designación, sin embargo, podría compaginar - en lo posible sin violentarla- la variedad de fenómenos y desarrollos musicales? ¿O pueden las designaciones de época ser reemplazadas por designaciones científicamente correctas? ¿Cuáles serían éstas? ¿Son divisiones aritméticas?

12 Incluiría aquí también a lo que se designa como "música del Renacimiento".

13 Cf. Dorner, Das Philosophon, p. 67.

${ }^{14}$ La primera época corresponde, en cierta medida, a la filosofía medieval, la cual en cuanto ancilla theologiae emprendió la tarea de hacer comprensibles en su racionalidad a los contenidos de la fe mediante la antigua metafísica de la sustancia; la segunda época corresponde de cierto modo a la "filosofía del yo" de la Edad Moderna. 
para "entretenimiento" la disolución de la lingualidad (Sprachlichkeit) y la belleza universal en todos los planos ${ }^{15}$. Su contenido central es la fija inmediatez de la libertad y la individualidad, del individuo en su inmediatez, irreconciliación e incomunicabilidad. Ella no configura una época ulterior en el sentido de los premodernos, sino que es la poshistoria -que existe como arte-del arte. ${ }^{16}$

La historia de la consumación de la música abarca, pues, un período de aproximadamente 1000 años.

\section{Sobre la lingualidad autónoma desde el Medioevo hasta la Edad Moderna en el ámbito de la música}

Quisiera ahora ocuparme con más detalle, en el sentido de una concreción ejemplar, de la primera época, a fin de mostrar cómo debería pensarse a partir de este enfoque la lógica de la aparición de la historia de la música.

El desarrollo del lenguaje musical capaz de autonomía comienza en la mímesis de la palabra propia del culto ${ }^{17}$, la cual alcanza en la polifonía vocal su

15 Cf. la tesis hegeliana de la "muerte del arte".

${ }^{16}$ Esta poshistoria comienza en los albores del siglo XIX y se consolida a más tardar con el inicio de la Primera Guerra Mundial. Ahora bien, desde la perspectiva de la mera modernidad, las cosas no se presentan de esta manera, sino que dicha perspectiva sostiene que la modernidad, a) no es un momento de la forma romántica del arte, sino una época autónoma que prosigue y acrecienta la razón artística de las épocas anteriores a la modernidad sin tener que servir a la religión; por tanto, b) que es la primera época realmente autónoma de arte, a la que pueden llegar a suceder todavía un sinnúmero de épocas ulteriores.

${ }^{17}$ La música "mundana” (la música popular, la música para bailar, la música cortesana, el minnesang, los maestros cantores) no juega hasta el siglo XV (los madrigales) un papel determinante para el desarrollo ulterior del potencial expresivo de la forma musical. También en los Países Bajos la música popular sirve sólo como material melódico en el marco de la música vocal "clerical”. Encontramos allí la práctica -que remite muy bellamente al espíritu del Medioevo musical- de adoptar como contrapunto en misas 
primer punto culminante. En el contenido de los movimientos polifónicos se expresa una unidad en la multiplicidad a nivel del contenido que es determinada en su figura y desarrollo primero por la palabra. Pero por esto la música no es sólo una servidora ${ }^{18}$, sino ya una representación autónoma de una humanidad, es decir, de una comunidad unificada por el contenido del cristianismo. A diferencia del canto coral, en el cual la música debe ser sólo una declamación elaborada de la palabra, en la textura musical de la música polifónica -en las relaciones y conducción de las voces- se explicita una relación a si que se determina de un modo progresivo de acuerdo con criterios racionales immanentes a la música. Este desarrollo se ejerce en la forma de un arco que atraviesa tres fases: una fase temprana, una fase alta y una tardía, es decir, de transición.

(1) La fase de formación del movimiento polifónico. Al comienzo, en los siglos XII y XIII, empezando con la escuela de Notre Dame, la igualdad abstracta, es decir, la falta de autonomía mutua de las voces. Alrededor del año $1300^{19}$ se diferencian y contraponen realmente las voces, las cuales ganan en autonomía (prohibición de las cuartas y quintas paralelas, etc.). De esto resulta la necesidad lógico-musical de la formación de una estructura rítmico-métrica que organiza las voces y de una notación correspondiente, en general, la necesidad lógico-musical de reglas sintácticas y gramaticales musicalmente autónomas de formación de una unidad en la multiplicidad. Las voces individuales tienen su determinidad en la relación con las voces a ellas

y motetes una melodía "mundana", incluso con su texto "mundano". Esto nos resulta extraño, porque proyectamos retroactivamente en la historia una limpia separación entre música mundana y música clerical. Un paralelo interesante en este respecto lo constituye la afición de la pintura de los Países Bajos a lo cotidiano (por ejemplo, las naturalezas muertas), que es presentado en su carácter de ser un fin en sí mismo.

${ }^{18} \mathrm{El}$ desarrollo de la polifonía estuvo por esta razón signado por debates sobre si puede concederse la particularización de la expresión musical, la multiplicidad de las voces a partir de la finalidad del servicio a la palabra (cfr. las discusiones en el Concilio de Trento; Palestrina debía decidir esta cuestión).

${ }^{19}$ Marchetto de Padua, Johannes de Muris; en el caso de este último aparece no por casualidad por primera vez la palabra "contrapunto" en lugar de el hasta entonces habitual término "discanto" o "diafonía" (así, por ejemplo, en Hucbaldo). 
contrapuestas y con la totalidad de su desarrollo. Éste es el significado propio de "contrapunto": punctus contra punctum. Polifonía no significa meramente una autonomía de las voces en el sentido de una heterofonía, sino que el punto decisivo es la configuración de una unidad coherente en la multiplicidad, en la cual se alcanza un equilibirio absoluto entre la autonomía de las voces; un equilibrio entre la pluralidad, por un lado, y la unidad de las voces en el automovimiento de la forma, por el otro. Pero la unidad de las voces es en esta primera fase -que llega hasta el fin del siglo XV- aún más extrínseca, una combinación regida por reglas (especialmente, técnicas canónicas -por ejemplo, Ocheghem).

(2) La fase de la configuración de una unidad que comprende las voces en la multiplicidad. Se plantea la tarea de dominar en el plano del estilo a tal punto lo artístico de esta forma que la forma compleja sea al mismo tiempo en cierto sentido natural, simple expresión del texto y su sustancia -una unidad de forma y contenido, unidad de suprema artificialidad y naturalidad. El ideal aparece como una textura musical en la cual lo importante es la mezcla de las voces más que su contraste. Para ello no se requiere sólo una mediación "linear" o sucesiva de las voces, sino al mismo tiempo también una mediación "vertical," simultánea. Por eso encontramos también a comienzos del siglo XVI una configuración de la unidad rítmico-métrica con mayor capacidad de expresión ("tactus") ${ }^{20}$. Con ello hemos alcanzado una etapa importante de la historia de consumación: por vez primera se alcanza bajo la figura de esta música un estar-mediada-en-sí-misma (Insichvermitteltheit) de la forma musical. Esto sucede a comienzos del siglo XVI en la escuela franco-flamenca; ante todo debe mencionarse aquí a Josquin des Prez. Su contemporáneo Martín Lutero da en el clavo con aquella famosa sentencia: "Josquin es el maestro de las notas, pues ellas deben hacer lo que él quiere; otros compositores, en cambio, deben hacer lo que las notas quieren" 21 . Josquin domina, pues, a tal punto el aspecto técnico de la forma que ésta desaparece como medio detrás

${ }^{20}$ Dos semibreves en uno y tres semibreves en uno.

${ }^{21}$ Esta famosa frase de Lutero, probablemente del año 1540, nos ha sido transmitida por su biógrafo Mathesius. Cfr. Johann Mathesius, Martin Luthers Leben, St. Louis und Dresden, 1883 (= Reprint von Mathesius, Historien, Von des Ehrwirdigen inn Gott seligen theuren Manns Gottes, D. Martin Luthers, Nuremberg, 1576), pp. 227-228. 
de su meta, esto es, detrás de la expresión del contenido -siguiendo aquí al ocultamiento de la técnica en la pintura (el nascondere l'arte). Con este logro se consuma el tránsito a la siguiente fase.

(3) "Música del Renacimiento" (alrededor del año 1400 hasta el 1600): la designación y ordenamiento de esta época es muy discutida en la ciencia de la música. Esto tiene un fundamento in re, pues la música es doble, como la cabeza de Jano. Por un lado, en el plano del estilo se alcanza en la polifonía vocal un pleno equilibrio entre forma mediada y simple expresión en el famoso "río sereno" de las voces (en la segunda mitad del siglo XVI, el "estilo de Palestrina") ${ }^{22}$. Con esto se consuma a comienzos del siglo XVI -y por cierto no provocado recién por las exigencias del Concilio de Trento- el tránsito en la polifonía vocal a una nueva forma de expresión del contenido del texto en el ámbito del estilo, a saber: en la consolidación de una estructura homófona que debe posibilitar una articulación musicalmente más adecuada de los contenidos de los pasajes textuales importantes.

Por otro lado, esta época ya ha puesto un pie en la Edad Moderna musical. La Edad Moderna musical se diferencia - por cierto, en el sentido de nuestra división- del Medioevo musical por el hecho que ella es la época de la consolidación y la consumación de la lingualidad autónoma desde el punto de vista musical. Con ella ya no se trata primariamente de la mímesis de un texto previamente dado, sino de la autoexplicación de lo bumanus en un lenguaje del sentimiento capaz de belleza. Los fundamentos de ello son sentados en cierto modo ya en la época del Renacimiento. Consideremos ahora los siguientes puntos:

- La formación de la "monodia" (Monteverdi), en la cual se muestra por primera vez la función organizadora de una genuina melodía sobre un acompañamiento simple. Con ello deviene posible una nueva profundidad y una nueva dramática de la expresión de las sensaciones.

- El surgimiento de nuevos géneros musicales “mundanos” hacia el final del Renacimiento (la ópera, el madrigal) y una música instrumental autónoma,

${ }^{22}$ Nombres ulteriores a ser mencionados son especialmente Orlando di Lasso, Tomás Luis de Victoria, William Byrd y Gregorio Allegri. 
máximamente artística. ${ }^{23}$ movimiento.

- La explícita consolidación de la homofonía en el plano del

- La formación de la sintaxis tonal en el plano de la sintaxis, así como, condicionado por ella, el desarrollo de nuevas técnicas de notación.

Tenemos, pues, en el plano del estilo, una oposición entre viejo y nuevo, entre prima prattica y seconda prattica. Esta oposición se radicaliza con la transición al Barroco a fines del siglo XVI y principios del XVII. Un contraste más extremo entre polifonía vocal compleja y monodia simple parece apenas pensable. Pero ¿es esta oposición un quiebre no-mediado, tal como parecerían sugerirlo las disputas históricas ${ }^{24}$ sobre la mímesis adecuada de la palabra y de su contenido? No obstante, es perfectamente posible ver una continuidad lógica interna que arroja paradigmáticamente luz sobre la lógica de la aparición histórica de la música -jmuy especialmente si se considera la tendencia que opera ya en dirección a la homofonía del "estilo Palestrina"! Pues lo que aquí sucede es aquello descrito por Hegel en su Fenomenología del espiritu, a saber: el progreso de una etapa de la conciencia a la siguiente. El resultado del desarrollo anterior se convierte en el objeto y punto de partida de un nuevo nivel y una nueva serie de desarrollos que constituyen la transición hacia el Barroco. El más alto logro de la prima prattica es la ya mencionada simple, tanto lineal como vertical estar-mediada-en-sí-misma de la textura musical. Con esto se ha configurado la estructura de una relación a sí -y esto es ahora puesto como tal de un modo musical, objetivo: precisamente en cuanto melodía bajo la figura de la monodia. A diferencia de la textura polifónica, el contenido que ha de ser expresado -se busca una expresión simple, evidente, "comprensible" de las sensaciones humanas- debe determinar inmediatamente el material sonoro formado. La música se orienta así según el gesto del hablar que ella (primeramente, en la música vocal) transforma para sí: en el fraseo, en la orientación al ritmo textual y en la escala cromática.

23 Aquí puede remitirse a la música para consort y, ante todo, a la música para instrumentos de teclado (Toccata, Preludium, Ricercar, Canzona).

${ }^{24}$ Es conocida la discusión del teórico Giovanni Artusi con Claudio Monteverdi. 
Éste es un giro decisivo: en la melodía se despliega la unidad de forma y contenido. Ella constituye el centro organizador del suceder musical. La melodía no es más, pues, una mera unidad sustancial en la multiplicidad, tal como sucede en el movimiento polifónico, sino el estar-mediado-en-sí-mismo que se despliega de un modo explícito u objetivo-musical, la relación a sí musicalmente existente ${ }^{25}$. La melodía es la lingualidad musical que ha alcanzado la subjetividad. La música renacentista constituye el tránsito a esto en la medida en que desarrolla por primera vez, partiendo del lenguaje, una lingualidad musical autónoma de los contenidos de la sensación. En el Barroco, esta lingualidad alcanzará un primer punto culminante en el desarrollo de un vocabulario diferenciado y una gramática de las figuras retórico-musicales.

El giro hacia la Edad Moderna en el plano de la música se correlaciona con el paso de la sustancia al sujeto en el plano de la filosofía. Destaco sólo brevemente dos puntos fundamentales:

(1) En referencia al movimiento: $\mathrm{Si}$ una voz es puesta como centro organizador del lenguaje musical, exige entonces un nuevo y revolucionario modo del movimiento, que se desplegará en la monodia constituida por el bajo continuo. Se trata, pues, del movimiento libre. En éste se diferencia la voz melódica dominante respecto de las voces acompañantes, las cuales sólo pueden reclamar una relativa autonomía, a saber: en cuanto momentos del desarrollo de la melodía. Si comparamos esto con la pintura de esta época, vemos que en el movimiento homófono la melodía hace de la perspectiva central organizadora, que se muestra como esta unidad en la medida en que se despliega en el horizonte de lo armónico y lo rítmico-métrico.

(2) Aun más fundamentalmente respecto del sistema tonal: el desenvolvimiento musical de esta relación a sí sólo es posible mediante un alejamiento del sistema de los modos (fines del siglo XVI) ${ }^{26}$ y la conformación de una sintaxis de tonos mayores y menores. La tonalidad hace posible la

${ }^{25}$ Cfr. Hegel, Vorlesungen über die Ästhetik III, Werke 15, 4. Auflage, Frankfurt am Main, Suhrkamp, 1995, p. 185.

${ }^{26}$ En la Edad Media la tercera fue primero considerada como disonancia; en el siglo XV encontramos ya el sonido de los acordes perfectos y hacia fines del siglo XVI se desploma el sistema de los modos como fundamento sintáctico. 
obviedad de una inmediatez que está absolutamente mediada en sí, o bien de una mediación que puede aparecer en la obviedad y evidencia de la inmediatez. La tonalidad posibilita una ritualidad formal, un cerrarse-sobre-sí-mismo que, como forma, es ya su propio contenido (esto se muestra en el material sonoro de las escalas, de la cadencia) así como un sistema que se media en sí mismo de afinidades sonoras (círculo de quintas). En cuanto esta sintaxis de la razón musical sin más abre primero un espacio real de desenvolvimiento para una lingualidad musical autónoma, no necesita de apoyo extrínseco alguno en un texto, sino que se habla únicamente a partir de sí misma. Resulta decisivo ver esto: recién en el ámbito de la sintaxis tonal deviene posible el automovimiento de la forma musical, la cual es su propio contenido; una música que es su propio lenguaje completo ("música absoluta"). Estas posibilidades universales de expresión de lo bumanus que se han abierto aquí serán finalmente diferenciadas y agotadas de modo único e irrepetible en sus géneros y estilos ulteriores por la Edad Moderna musical en sus tres grandes fases siguientes del Barroco, el Clasicismo y el Romanticismo.

Traducción de Leonardo Abramovich y Héctor Ferreiro 